\title{
Drought Relief and Reversal over North America from 1500 to 2016 음
}

\author{
M. C. A. Torbenson, ${ }^{a}$ D. W. Stahle, ${ }^{b}$ I. M. Howard, ${ }^{b}$ D. J. Burnette, ${ }^{c}$ D. Griffin, ${ }^{d}{ }^{\text {J. Villanueva-Díaz, }},{ }^{\mathrm{e}}$ \\ AND B. I. $\mathrm{COOK}^{\mathrm{f}, \mathrm{g}}$ \\ ${ }^{a}$ Department of Civil, Environmental and Geodetic Engineering, The Ohio State University, Columbus, Ohio \\ ${ }^{\mathrm{b}}$ Department of Geosciences, University of Arkansas, Fayetteville, Arkansas \\ ${ }^{\mathrm{c}}$ Department of Earth Sciences, University of Memphis, Memphis, Tennessee \\ ${ }^{\mathrm{d}}$ Department of Geography, Environment and Society, University of Minnesota, Minneapolis, Minnesota \\ e INIFAP, Gomez Palacio, Durango, Mexico \\ ${ }^{\mathrm{f}}$ Lamont-Doherty Earth Observatory, Columbia University, Palisades, New York \\ ${ }^{\mathrm{g}}$ NASA Goddard Institute for Space Studies, New York, New York
}

(Manuscript received 7 October 2020, in final form 11 May 2021)

\begin{abstract}
Season-to-season persistence of soil moisture drought varies across North America. Such interseasonal autocorrelation can have modest skill in forecasting future conditions several months in advance. Because robust instrumental observations of precipitation span less than 100 years, the temporal stability of the relationship between seasonal moisture anomalies is uncertain. The North American Seasonal Precipitation Atlas (NASPA) is a gridded network of separately reconstructed cool-season (December-April) and warm-season (May-July) precipitation series and offers new insights on the intra-annual changes in drought for up to 2000 years. Here, the NASPA precipitation reconstructions are rescaled to represent the long-term soil moisture balance during the cool season and 3-month-long atmospheric moisture during the warm season. These rescaled seasonal reconstructions are then used to quantify the frequency, magnitude, and spatial extent of cool-season drought that was relieved or reversed during the following summer months. The adjusted seasonal reconstructions reproduce the general patterns of large-scale drought amelioration and termination in the instrumental record during the twentieth century and are used to estimate relief and reversals for the most skillfully reconstructed past 500 years. Subcontinental-tocontinental-scale reversals of cool-season drought in the following warm season have been rare, but the reconstructions display periods prior to the instrumental data of increased reversal probabilities for the mid-Atlantic region and the U.S. Southwest. Drought relief at the continental scale may arise in part from macroscale ocean-atmosphere processes, whereas the smallerscale regional reversals may reflect land surface feedbacks and stochastic variability.
\end{abstract}

KEYWORDS: Drought; Climate variability; Paleoclimate; Rainfall

\section{Introduction}

The negative impact of growing-season drought on society is well documented (e.g., Wilhite 2000; Ault 2020). Drought conditions affecting crop productivity at the start of the growing season tend to persist throughout the period of plant growth because of hydrological processes in the soils (Palmer 1965). In some regions, there is also a degree of interseasonal autocorrelation in precipitation that can exacerbate extreme drought conditions. The persistence of soil moisture deficits is a common feature of growing-season drought over the central United States (e.g., Dong et al. 2011) and has modest value for probabilistic agroeconomic and hydrological forecasting (Huang et al. 1996; Otkin et al. 2015). Occasionally, early growing-season drought over North America is relieved (ameliorated) during the

Supplemental information related to this paper is available at the Journals Online website: https://doi.org/10.1175/EI-D-20-0020.s1.

Corresponding author: Max C. A. Torbenson, torbenson.1@ osu.edu

Earth Interactions is published jointly by the American Meteorological Society, the American Geophysical Union, and the Association of American Geographers. subsequent summer months and very rarely can drought be fully reversed (terminated) by exceptional summer rainfalls (Karl et al. 1987). The unusually heavy rainfalls following the spring droughts experienced in the Four Corners region in 1967 and in the central Appalachian Mountains in 2001 are examples of exceptional interseasonal drought reversals (Schneider et al. 2018).

The amelioration and termination of drought is difficult to study because there have been few examples in the instrumental hydroclimatic record. There is some potential to use proxy treering records to explore the persistence and relief of drought, but most tree-ring proxies represent interannual changes in the longterm soil moisture balance (e.g., Cook et al. 1999, 2010; Stahle et al.2016) while the investigation of intra-annual or interseasonal drought requires tree-ring data with a strong subannual moisture response. Discrete seasonal precipitation reconstructions are now available for the cool [December-April (DJFMA)] and warm [May-July (MJJ)] portions of the year in the North American Seasonal Precipitation Atlas (NASPA; Stahle et al. 2020). The gridded NASPA reconstructions were designed to mimic the level of cool to warm-season moisture persistence measured in the instrumental precipitation observations, using tree-ring chronologies with a climate response unique to each season.

The NASPA provides a new opportunity to quantify the frequency, magnitude, and spatial extent of drought relief and reversal over North America during centuries prior to instrumental observations. This article presents a quantitative 


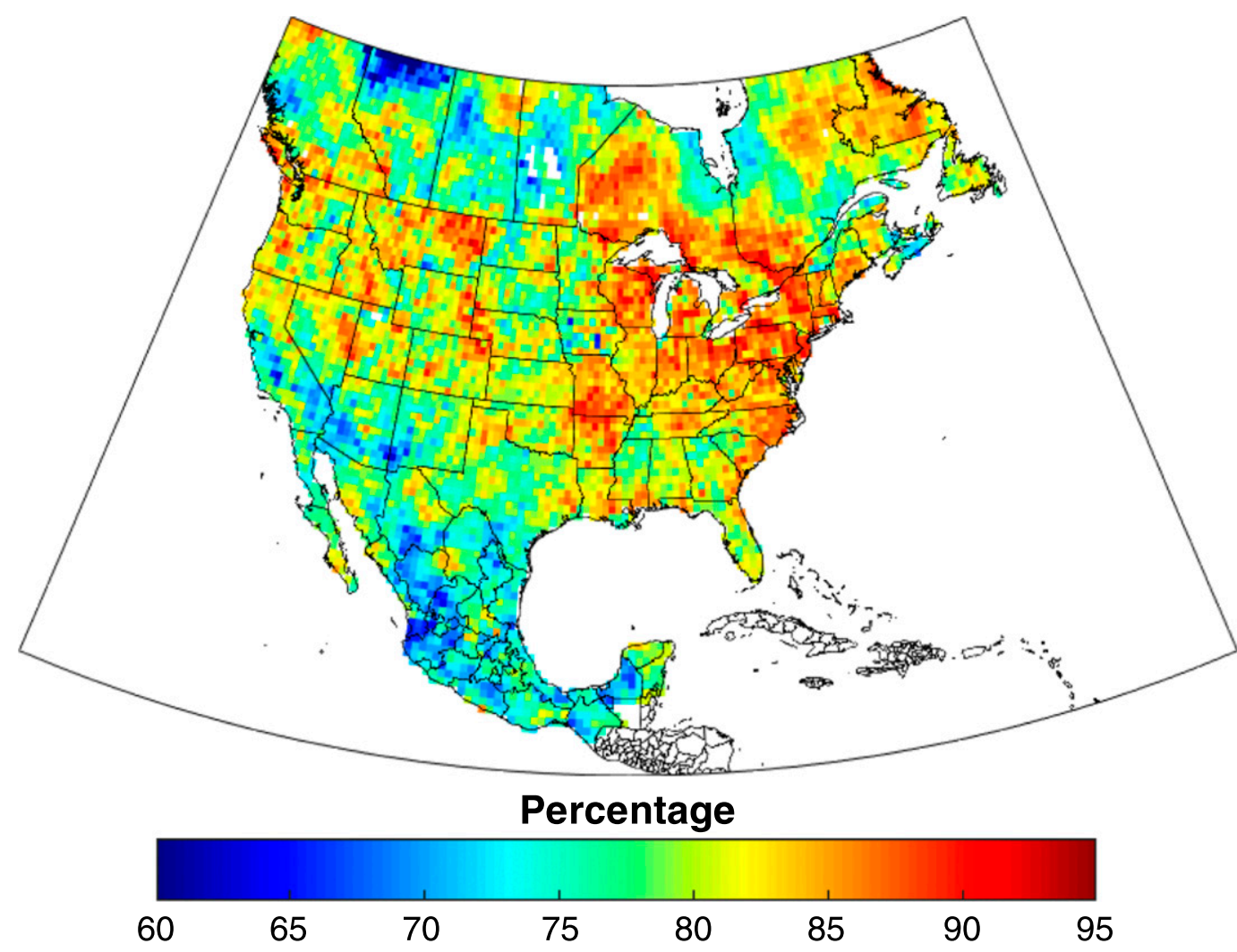

FIG. 1. The persistence of cool-to-warm-season drought is illustrated as the percentage of years in which instrumental PDSI was $\leq-2$ in both April and the following July (1895-2016).

analysis of intra-annual changes in drought conditions in the instrumental and reconstructed cool- and warm-season precipitation (and derived moisture estimates) data for North America. We adopt the framework used by Karl et al. (1987) for their investigation of drought termination in the United States and apply it to the NASPA reconstructions. This article details the methods used to rescale the reconstructed precipitation into units equivalent to those used by Karl et al. (1987). Results are presented at the continental scale and for two selected regions with diverse precipitation climatology and where the seasonal precipitation reconstructions included in the NASPA have strong season-to-season calibration and validation skill.

\section{Background}

The persistence of growing-season drought over North America is illustrated in Fig. 1, which depicts the fraction of years suffering at least moderate April drought [Palmer drought severity index (PDSI) $\leq-2$ ] that were still in moderate drought by the end of the following July (PDSI $\leq-2$ ), based on the gridded instrumental PDSI data of van der Schrier et al. (2013). These data indicate that the chance of April drought (PDSI $\leq-2)$ persisting through July (PDSI $\leq-2$ ) is at least $60 \%$ for the entire North American study area, based on the slow accumulation and depletion of soil moisture in the PDSI model (Palmer 1965). In fact, over $75 \%$ of the years in April drought were still experiencing drought in the subsequent July for most of the continental United States and eastern Canada (Fig. 1). The lowest levels of cool- to warmseason drought persistence are observed in Mexico and the U.S. Southwest (Fig. 1), likely due to the disconnect between cool-season precipitation and the North American monsoon (Adams and Comrie 1997). The overall strong continuation of cool-season to warm-season drought affects both the humid and arid regions of North America and include severe sustained drought episodes such as that in the 1950s (Andreadis et al. 2005).

The interseasonal persistence of drought can provide some skill when forecasting future conditions (Hao et al. 2014; Otkin et al. 2015; Betts et al. 2017). In midlatitude regions such as the continental United States, land surface feedbacks are thought to be the main driver of predictability on time scales greater than a single month (Huang et al. 1996; Koster et al. 2000). Soil moisture can influence the supply of water vapor to the atmosphere and is responsible for some of the observed continuation of drought during the growing season (Betts et al. 1996; Maurer et al. 2002). However, the season when drought termination is most likely varies across North America (Karl et al. 1987) due to differences in local and regional climatology. In Mediterranean climates, such as in Southern California, warmseason precipitation makes up such a small portion of the annual total that even significant positive anomalies have little practical impact on drought conditions (Polade et al. 2017). 


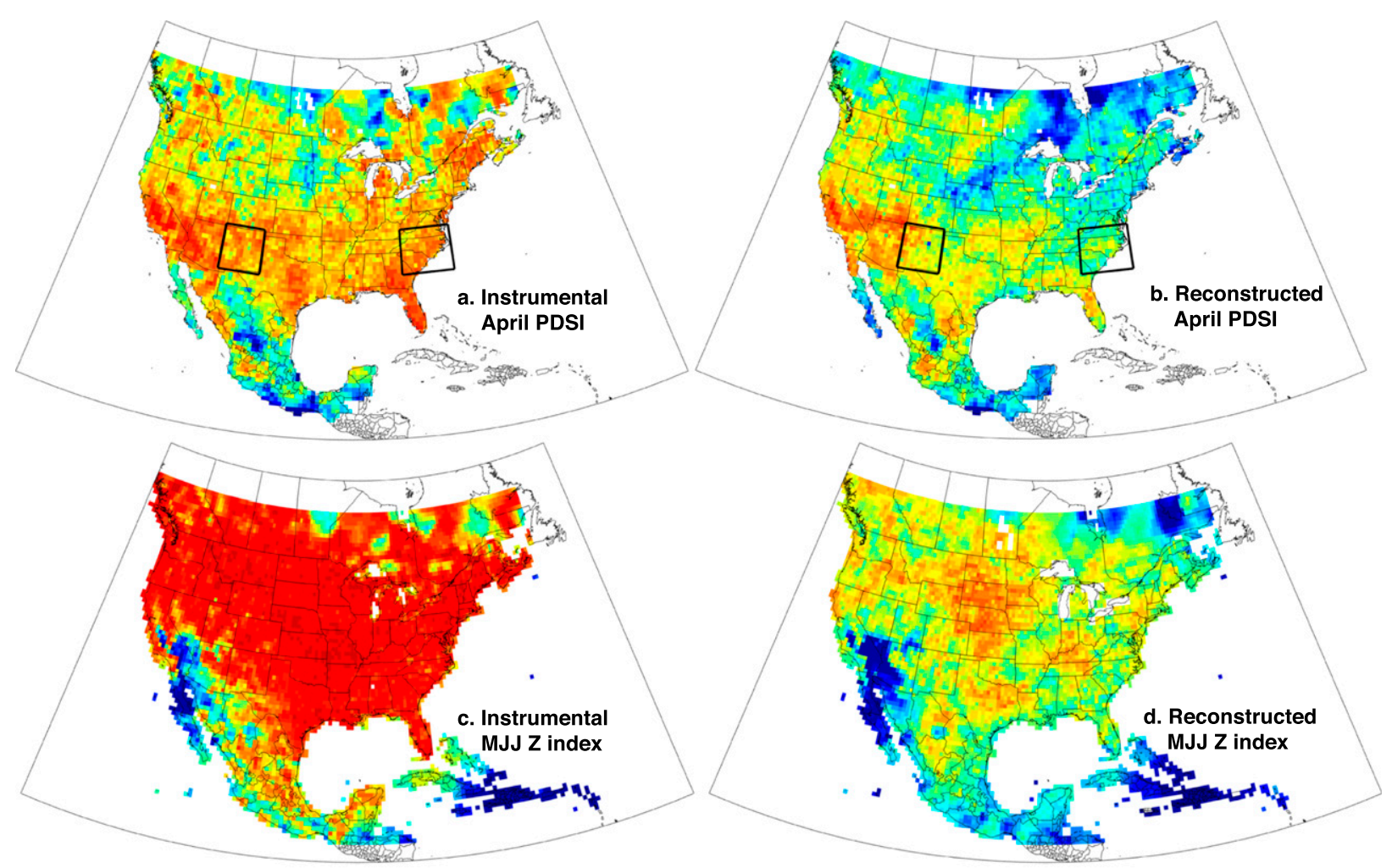

Correlation

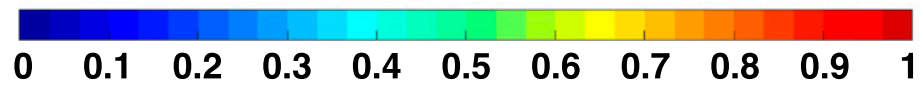

FIG. 2. Gridded correlations between (a) instrumental DJFMA SPI and April PDSI and (b) reconstructed DJFMA SPI and instrumental April PDSI for the period 1928-78. The two regions studied are indicated by black outlines. Also shown are the correlations for (c) instrumental MJJ SPI and MJJ $Z$ index and (d) reconstructed MJJ SPI and instrumental MJJ $Z$ index.

The North American monsoon (NAM) plays an important role in mitigating summer drought in the U.S. Southwest (Adams and Comrie 1997; Griffin et al. 2013) and on the East Coast, summer precipitation contributes to a larger portion of the annual total and can offset large deficits in early growingseason soil moisture.

The magnitude of persistence in early to late growing-season drought in the instrumental record is not equal across space (Fig. 1; Karl et al. 1987) and it may not be stable over time (e.g., Zhu et al. 2005). Previous studies have suggested that ocean-atmospheric factors may be involved in low-frequency changes in the level of correlation between seasonal moisture conditions (e.g., Zhu et al. 2007; Torbenson and Stahle 2018). Proxy tree-ring reconstructions of seasonal moisture levels can therefore potentially contribute to the specific analysis of the interseasonal moisture relationships as they pertain to low frequency variability.

\section{Methods and data}

Gridded reconstructions of independent cool- and warmseason precipitation totals and the standardized precipitation index (SPI) were developed by Stahle et al. (2020) using 439 tree-ring chronologies with a discrete cool-season response, and
547 with a separate warm-season signal. The reconstruction targets were Global Precipitation Climatology Center data (GPCC; Becker et al. 2013; Schneider et al. 2018) for the cool (DJFMA) and warm (MJJ) season at each $0.5^{\circ}$ grid point between $14^{\circ}$ and $55^{\circ} \mathrm{N}$ and $50^{\circ}$ and $135^{\circ} \mathrm{W}$. At each grid point, a point-by-point regression (Cook et al. 1999) was performed with surrounding tree-ring chronologies as predictors for a total of 16 ensembles. A procedure to spatially smooth the estimates was applied during the reconstruction process to extend estimates for certain grid points (as adjacent grid points may go farther back in time) and to lessen the impact of outliers at individual grid points. Each reconstructed time series was reestimated through a ninepoint kernel regression, based on the time series and surrounding eight grid points. See Stahle et al. (2020) for a full description of the reconstruction method. The resulting ensemble mean cool and warm-season reconstructions both display significant skill in estimating precipitation anomalies during the twentieth-century calibration and verification periods over most of the continent (Stahle et al. 2020). The gridded "persistence free" warm-season reconstructions (warmPF) dating from 1400 to 2016 were produced to minimize the correlation between the cool- and warmseason estimates remaining over some portions of North America, despite the fact that the reconstructions were based on discrete 

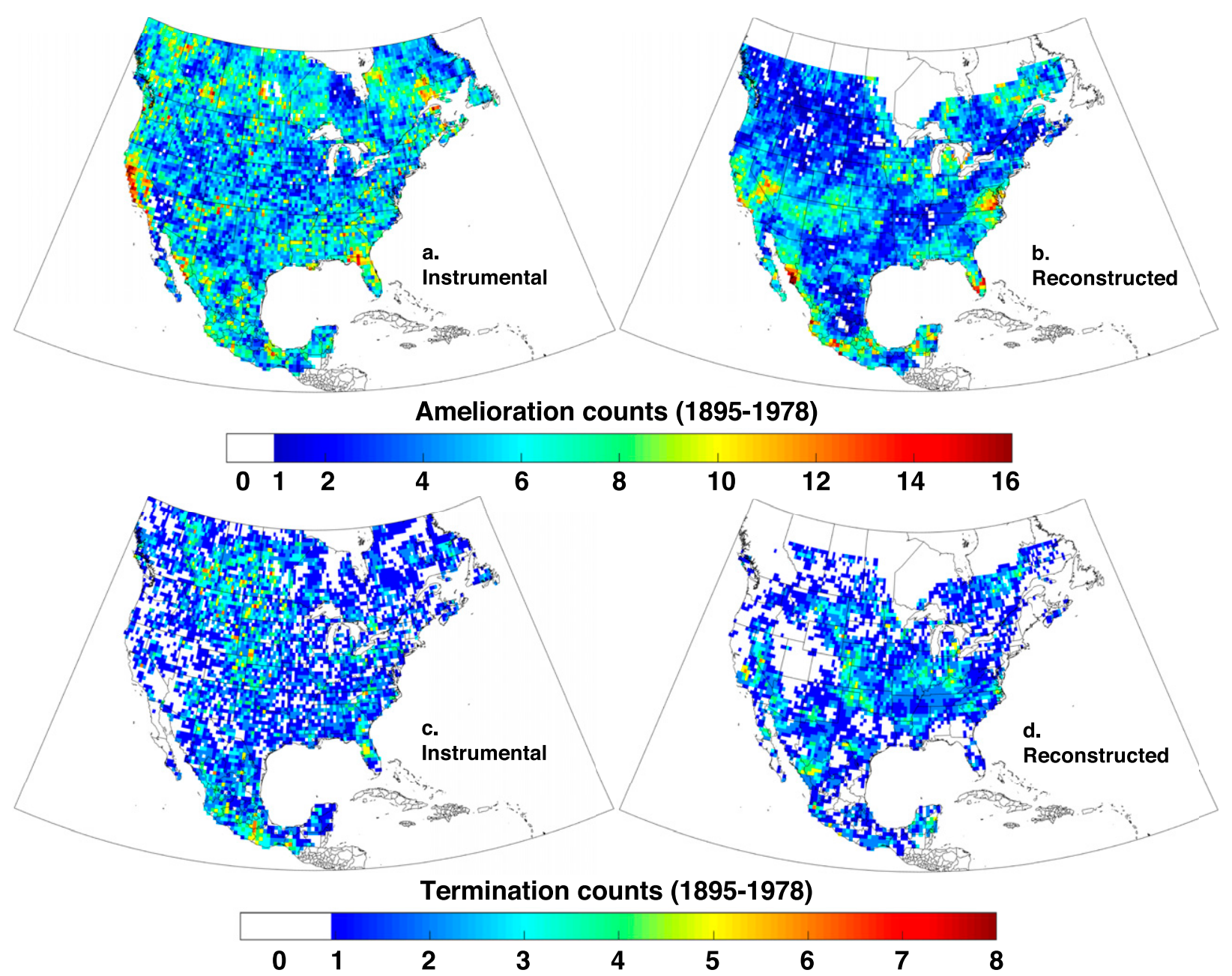

FIG. 3. The number of relief (or amelioration) events of April drought in the following May-July period at each grid point over the 84-yr interval from 1895 to 1978 [per Karl et al. (1987)] for (a) instrumental PDSI and $Z$ index data and (b) rescaled reconstructions. Also shown are the number of reversal (or termination) events of April drought in the following May-July period at each grid point for (c) instrumental and (d) reconstructed data.

predictors (Stahle et al. 2020). Any exaggerated correlation between cool- and warm-season reconstructions is assumed to be due to biological memory, and therefore only add bias to the latter (i.e., the warm-season reconstructions). Therefore, the cool and warmPF estimates are used in the analyses below.

The PDSI (Palmer 1965) is a model estimate that integrates several months of previous rainfall and temperature to fit the long-term variations of soil moisture. The $Z$ index is an intermediate calculation in the Palmer model used to estimate atmospheric moisture availability prior to the integration of preceding conditions (Heim 2002). There is a strong correlation between cool-season DJFMA precipitation totals and the April PDSI in both the instrumental and reconstructed data drawn from the NASPA (as will be shown below). Warm-season (MJJ) precipitation is also well correlated with the averaged MJJ $Z$ index, using both instrumental and reconstructed data (see below). These strong relationships between cool-season precipitation and April soil moisture, and warm-season precipitation and MJJ $Z$ index, can be used to develop quantifiable estimations of past drought reversals. At each grid point, the coolseason SPI reconstruction was rescaled to the distribution of April PDSI using linear regression for the calibration period (1928-78). The same procedure was performed for the warmseason SPI reconstructions with an MJJ $Z$ index target. For any year with an estimated PDSI of $\leq-2$, the potential of a drought reversal was analyzed. The thresholds for amelioration of April droughts were based on Karl et al. (1987):

$$
y=-0.8 x-0.55
$$

where $y$ is the minimum 3-month MJJ $Z$ index value necessary to ameliorate/relieve 1-month PDSI drought of $x$, and

$$
y=-0.8 x-0.20
$$

where $y$ is the minimum 3-month MJJ Z index value necessary to terminate/reverse a 1-month PDSI drought of $x$. 


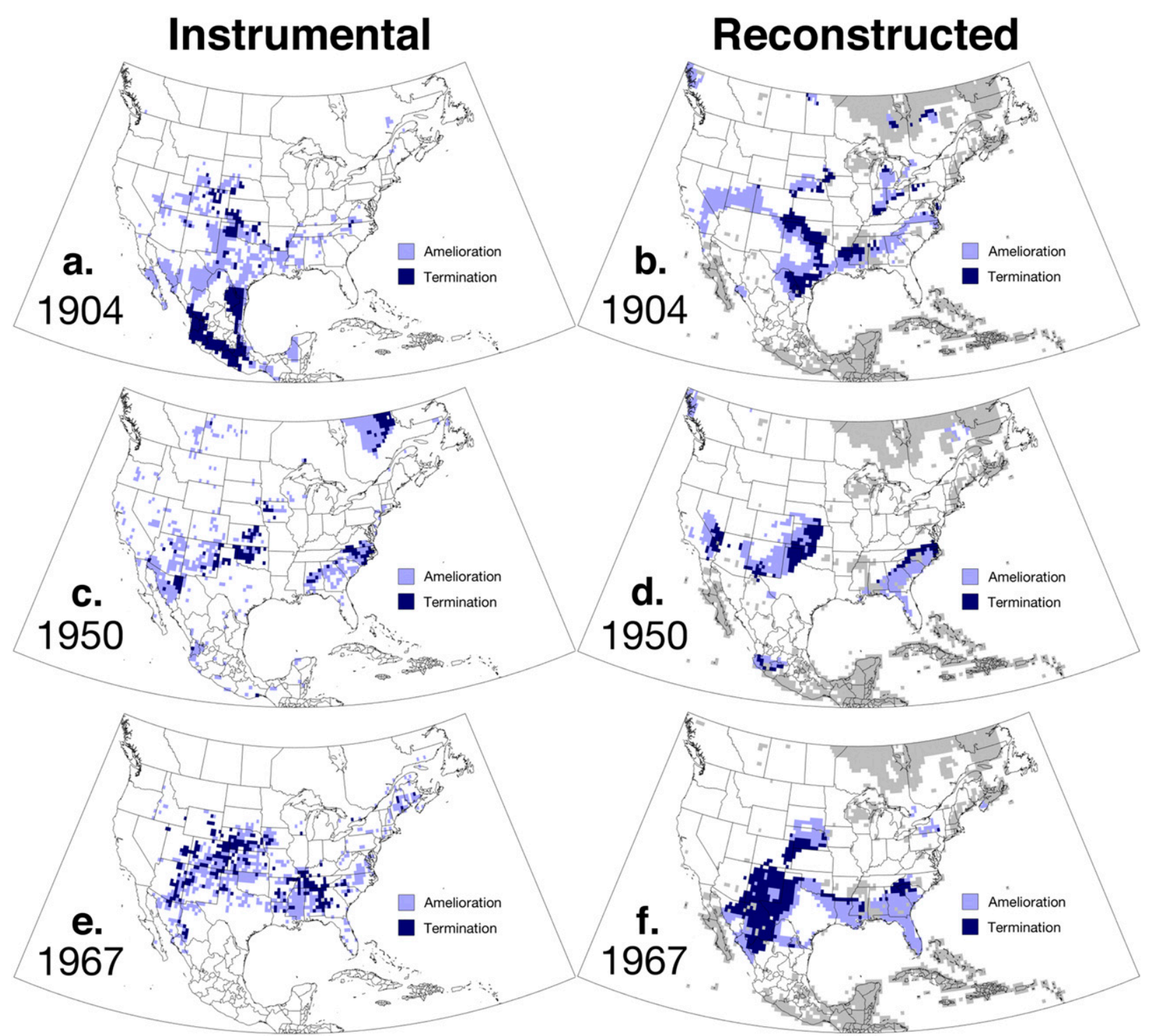

FIG. 4. Drought amelioration and termination are mapped for (left) instrumental and (right) reconstructed data for (a),(b) 1904; (c),(d) 1950; and (e),(f) 1967. Gray areas lack reconstruction skill on one or both seasons.

Equations (1) and (2) were used to calculate the relief and reversal of drought in April based on the instrumental and reconstructed values of April PDSI and MJJ $Z$ index estimated from the NASPA. Drought relief and reversal due to summer precipitation was calculated for every grid point in the reconstructed domain for each year of reconstructed data (15001978). The continental-scale analyses were limited to all North American grid points between $23.75^{\circ}$ and $41.75^{\circ} \mathrm{N}$ because of weaker reconstruction skill outside these latitudes.

Two regions were selected to highlight the seasonal evolution of drought in the instrumental and preinstrumental eras: 1) the mid-Atlantic (MATL; 32.25-37.75 ${ }^{\circ} \mathrm{N}, 75.25-82.75 \mathrm{~W}^{\circ}$ ); and 2) Southwest (SW; $31.75-37.25^{\circ} \mathrm{N}, 103.25-109.25^{\circ} \mathrm{W}$; i.e., New Mexico) (Fig. 2). These regions were selected in part because the precipitation reconstructions are skillful for both seasons [the leave-one-out cross-validation reduction of error (CVRE) $>$ 0.20; Stahle et al. 2020]. These regions also have contrasting seasonal precipitation climatology, providing a range of conditions to test the frequency of drought relief and reversal. The two study regions were affected by one or both of the most severe persistent droughts of the twentieth century, the Dust Bowl drought of the 1930s and the 1950s drought. Within each regional box, the number of grid points experiencing April drought $(\mathrm{PDSI} \leq-2$; PDSI $\leq-3$; PDSI $\leq-4)$ was counted for each year of record, as well as the number of grid points for which drought was relieved or reversed in the subsequent three months (i.e., ameliorated or terminated). Counts were computed and compared for the instrumental and reconstructed data to assess how well the reconstructions track drought relief and reversal, both temporally and spatially, within each region. 


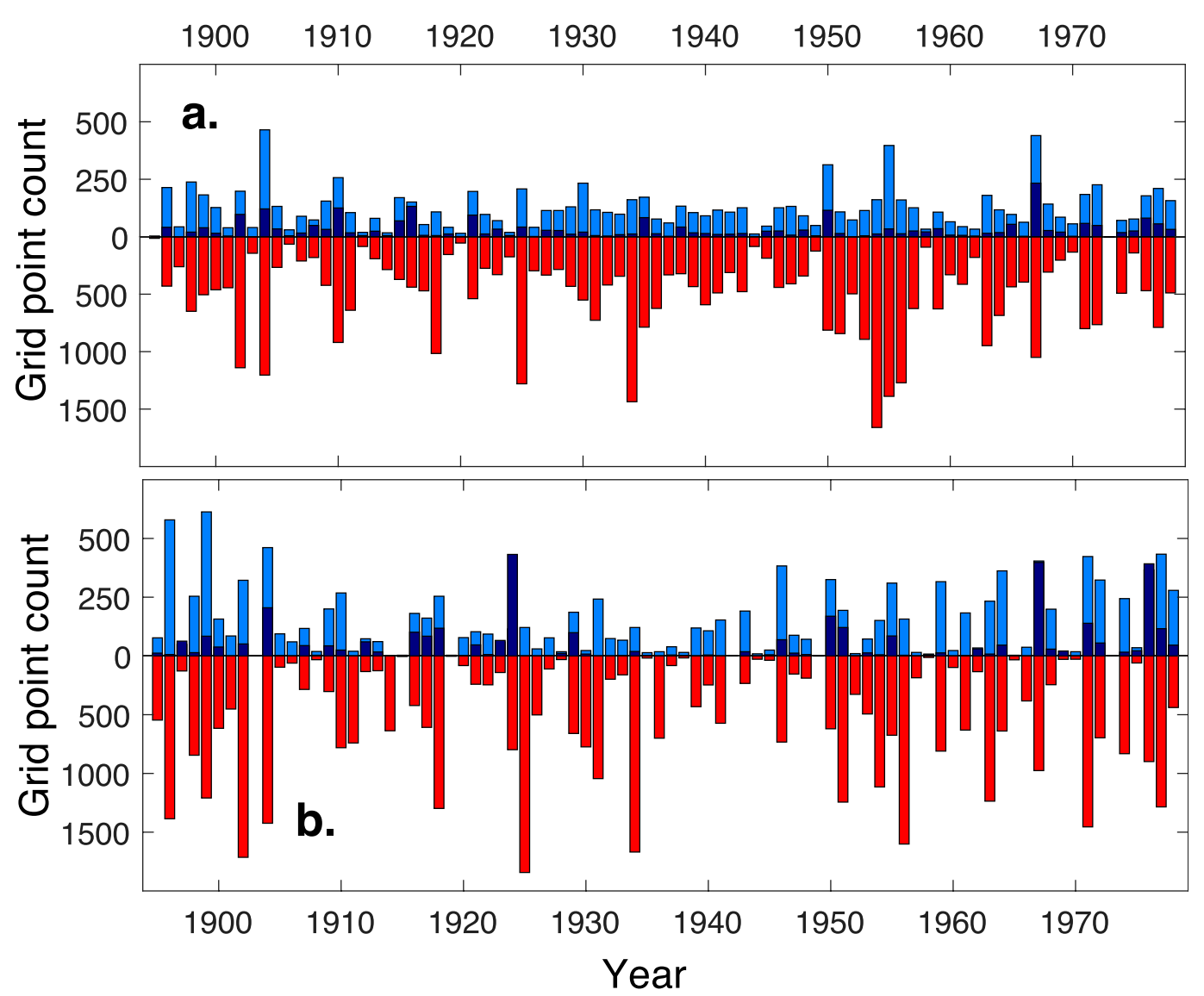

FIG. 5. The number of grid points across North America that recorded drought in April (i.e., April PDSI at or below -2.0 ; red histograms) and the number of these points that were then ameliorated or terminated (blue and dark blue, respectively) for the (a) instrumental data and (b) reconstructed data for the common period 1895-1978.

\section{Results and discussion}

\section{a. Estimating spring and summer drought over North America}

To estimate the impact of summer rainfall on long-term agricultural drought, cool- and warm-season precipitation data were compared to April PDSI and MJJ $Z$ index (Palmer 1965; Heim 2002). Instrumental precipitation for DJFMA is highly correlated with April PDSI across most of the continental United States (Fig. 2a). The relationship between reconstructed DJFMA precipitation and instrumental April PDSI is overall weaker (Fig. 2b) and reflects spatial variability of skill in the reconstructions. However, below $40^{\circ} \mathrm{N}$ the DJFMA reconstructions reproduce the instrumental DJFMA correlations with April PDSI reasonably well. Similarly, instrumental MJJ precipitation is highly correlated with the MJJ $Z$ index (Fig. 2c; Heim 2002), because of the large role that precipitation plays in the calculation of $Z$. The warmPF reconstructions are also highly correlated with instrumental MJJ $Z$ and reproduce the spatial pattern of lower correlations (i.e., over Baja California and western Mexico; Fig. 2d). The spatial smoothing applied to the gridded estimates during the reconstruction phase introduces additional uncertainty to the analyses of changing drought conditions. However, the percentages of grid points ameliorated and terminated during the common instrumental period are similar between observed and reconstructed data at a continental scale (see below).

\section{b. Continentwide analyses}

Years with sufficient summer precipitation to alleviate and or terminate April drought conditions have been rare across North America, in both instrumental and reconstructed data (Fig. 3). The highest levels of April drought relief in the following summer during the 1895-1978 common period were observed over the Southeast and over portions of Mexico and the Southwest (Figs. 3a,b). The full reversal of April drought did not exceed three events in the 84-yr period from 1895 to 1978 for most of the continent (Figs. 3c,d). The highest number of reversals at any grid point was only six in either the instrumental or reconstructed data. Terminations appear to be most frequent over portions of the Great Plains in both the instrumental and reconstructed data, and the reconstructions indicate more reversal events over the Ohio Valley than is apparent in the instrumental observations. The increased rate of reversal events in the reconstructions likely stem from using the warmPF version of the warm-season estimates, which removes some of the persistence present in the instrumental data. Lower (or deflated) 

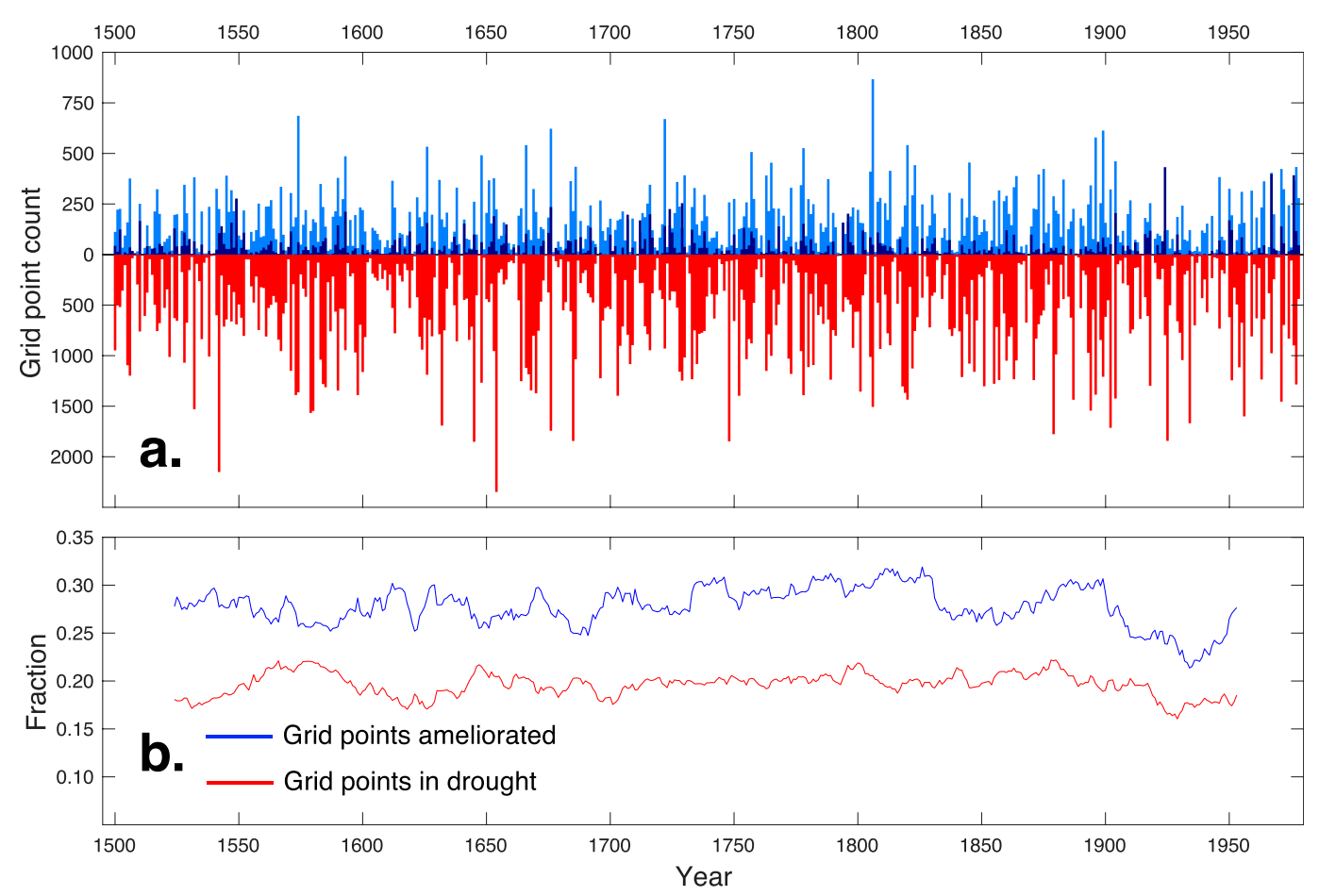

FIG. 6. (a) The number of grid points across North America that experienced at least moderate April drought (red color), and amelioration and termination in the subsequent summer months, for 1500-1978 based on the rescaled reconstructions (blue colors). (b) The 49-yr running mean of the fraction of continental grid points that displays at least moderate April drought (PDSI $\leq-2$ ), and the fraction of those grid points experiencing amelioration in the subsequent summer months.

correlations result in a lower likelihood of years with same sign (e.g., dry-dry), thus increasing the chance of relief/reversal events.

Spatial patterns of drought relief and reversals are illustrated in Fig. 4. Summer precipitation alleviated spring drought over portions of the southern United States and Mexico in the instrumental data during 1904, 1950, and 1967 (Figs. 4a,c,e). Wilmington, North Carolina, for example, witnessed the highest two-day nonhurricane precipitation total on record on 7-8 July 1950. The differences in spatial detail between instrumental and reconstructed data are evident in these maps but the reconstructions reproduce the regional patterns of drought relief and reversal reasonably well, including the year 1904 during the precalibration period (Figs. 4b,d,f).

The continentwide grid points that recorded the relief and reversal of April drought (PDSI $\leq-2$ ) during the following MayJuly period are counted for the instrumental and reconstructed data in Fig. 5 (1895-1978). The timing of relief and reversal agrees well between the instrumental and reconstructed data, and the frequency is only marginally higher in the reconstructions (instrumental: $24.6 \%$ relief $/ 5.8 \%$ reversal; reconstructed: $27.9 \% / 6.7 \%$ ). Thus, the reconstructions can provide useful information on the frequency and spatial extent of drought relief and reversals during both the instrumental and, presumably, the preinstrumental eras. Prior to the instrumental period, the reconstructions record similar probabilities for relief and reversals (Fig. 6). For the period 15001894, the percentage of grid points in April drought that were then ameliorated in the following summer was $28.0 \%$, and $6.2 \%$ recorded full reversals.
Nine additional years of reconstructed drought relief are mapped during the preinstrumental period in Fig. 7. The maps in Figs. 4 and 7 indicate that drought relief generally occurs at the regional scale. Convective systems at these scales are thought to account for nearly $75 \%$ of heavy summer rainfall events (Schumacher and Johnson 2006). A tropical storm is recorded by historical documents in early June of 1805 near Louisiana (Mock 2008) (Fig. 7h). In some cases, the spatial pattern of relief is organized into structures that resemble frontal boundaries (e.g., Figs. 4c,d and 7d,f,g,i). The rarity and regional nature of relief and reversal both suggest that the dynamics responsible for drought amelioration and termination over North America may be associated with unseasonably strong local weather patterns.

The precipitation and temperature changes required to relieve if not fully reverse an April drought below a PDSI threshold of $\leq-2.0$ are substantial and often involve simultaneous changes in atmospheric circulation patterns over the midlatitudes of the North Pacific and North America (Zhou et al. 2019). Composite map analyses of instrumental 500-hPa geopotential height data during the 10 years of greatest drought relief extent in the instrumental (1896, 1898, 1904, 1910, 1930, 1950, 1955, 1967, 1971, 1977) and reconstructed (1896, 1899, 1904, 1946, 1950, 1964, 1967, 1971, 1976, 1977) time series are presented in Fig. 8, using gridded NCEP-NCAR Twentieth Century Reanalysis data (Slivinski et al. 2019). The 500-hPa geopotential height field composites indicate high 

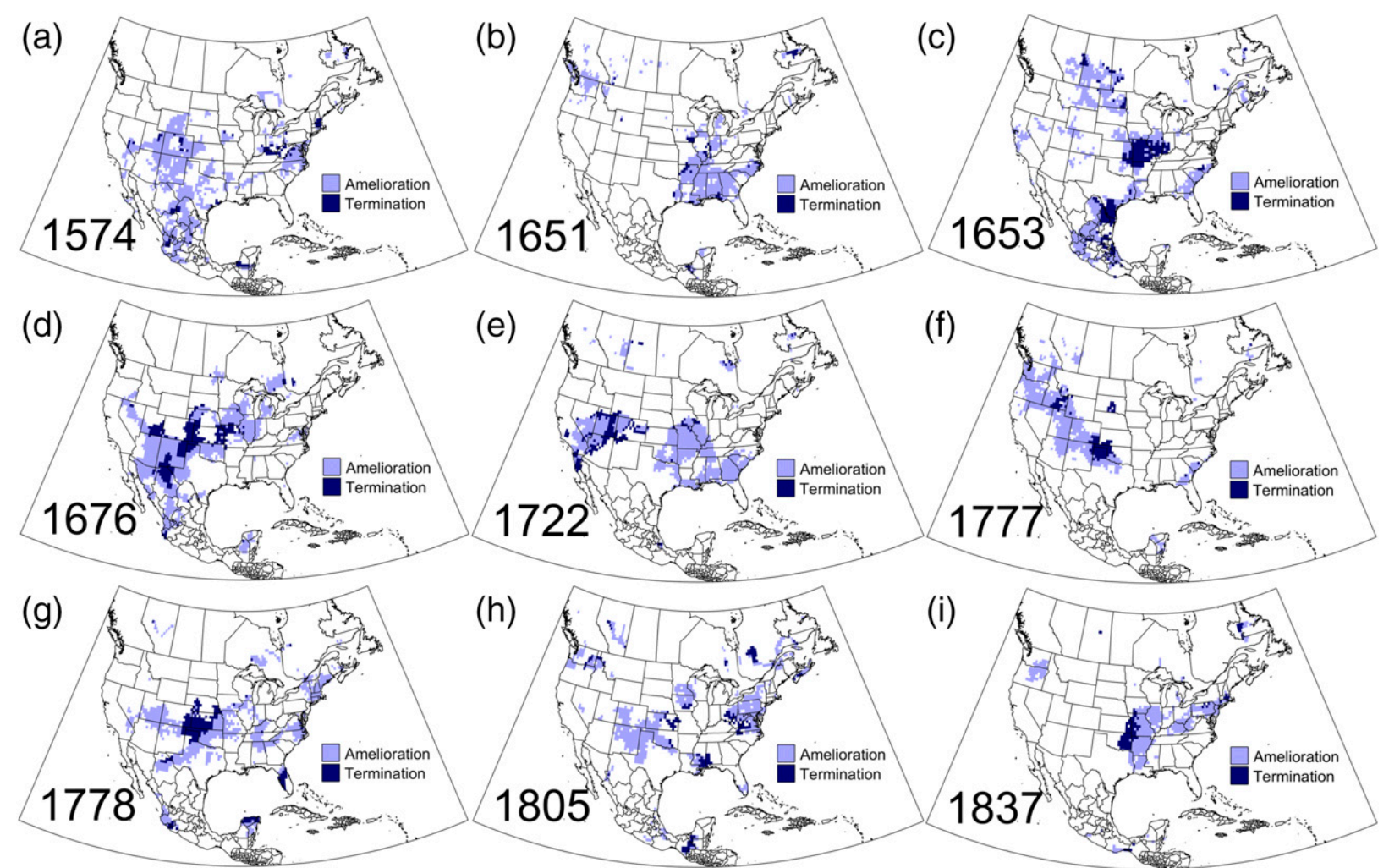

FIG. 7. Examples of exceptional drought relief over North America over the past 500 years, based on reconstructed moisture anomalies.

pressure over the North Pacific with a weak or nonexistent trough over the Gulf of Alaska and British Columbia. High pressure is also present over the western and central United States, favoring widespread drought over North America during the cool season (Figs. 8a,b). In the subsequent warm season, the conditions weaken and anomalously low 500-hPa height patterns developed over the western United States (Figs. 8c,d). These pressure changes would promote wetter and cooler conditions during the summer months. Large changes in the vector winds and surface air temperature fields also occurred during these 10 years of drought relief over the United States, with a shift from southerly to northerly mean flow over central North America, contributing to well below average surface air temperatures during the warm season (not shown). Global sea surface temperatures (SST) during the top 10 years of drought relief over North America are characterized by cold conditions in the equatorial Pacific Ocean, similar to the La Niña forcing noted for the cool-season reconstruction (Stahle et al. 2020), which weaken in the subsequent months (Fig. S1 in the online supplemental material). These composite analyses therefore suggest that large-scale drought relief and reversal events are primarily linked with major atmospheric circulation changes over the Pacific-North American sector (Fig. 8) and not with persistent and recurrent anomalies in the global SST field. However, note that counts that are based on the full North American continent may fail to capture some of the finer details in the relationship with atmospheric circulation patterns.

\section{c. Regional analyses}

As with the continental-scale results, the reconstructed percentages of drought relief and reversal for the two regions are close to the instrumental data for the overlapping period 18951978 (Table 1). The reconstructions underestimate amelioration by $12.3 \%$ and termination by $1.6 \%$ in MATL, and overestimate amelioration by $0.5 \%$ and termination by $3.0 \%$ in SW. There is a general agreement between reconstructed and instrumental relief/reversal events for individual years, as exemplified by the 1950s (calibration period) and the first decade of the twentieth century (verification period) (Fig. 9). The extensive MATL drought in 1950 was cancelled, or at least lessened, by summer rainfall at most grid points in both the instrumental (Fig. 9b) and reconstructed data (Fig. 9d). Fewer grid points experienced relief in 1955. Although the droughts of 1904-5 and 1910-11 are more spatially extensive in the reconstructed data (Fig. 9c), the relative magnitude of amelioration/termination mimics that of the instrumental data (Fig. 9a). During the 1950s drought, the Southwest mainly experienced relief in 1950 and 1955 (Fig. 9f), which is recorded by the tree-ring-based estimates (Fig. 9h). The region saw some relief in 1899 and 1904, but little to none in 1900, 1902, and 1910 (Figs. 9e,g). The contrasting differences between high and low amelioration during years of extensive drought suggest that the NASPA reconstructions have some skill in distinguishing spatial extent of relief at regional scales.

The mid-Atlantic region has had a relatively high probability of drought relief and reversal compared to the continental 
Instrumental
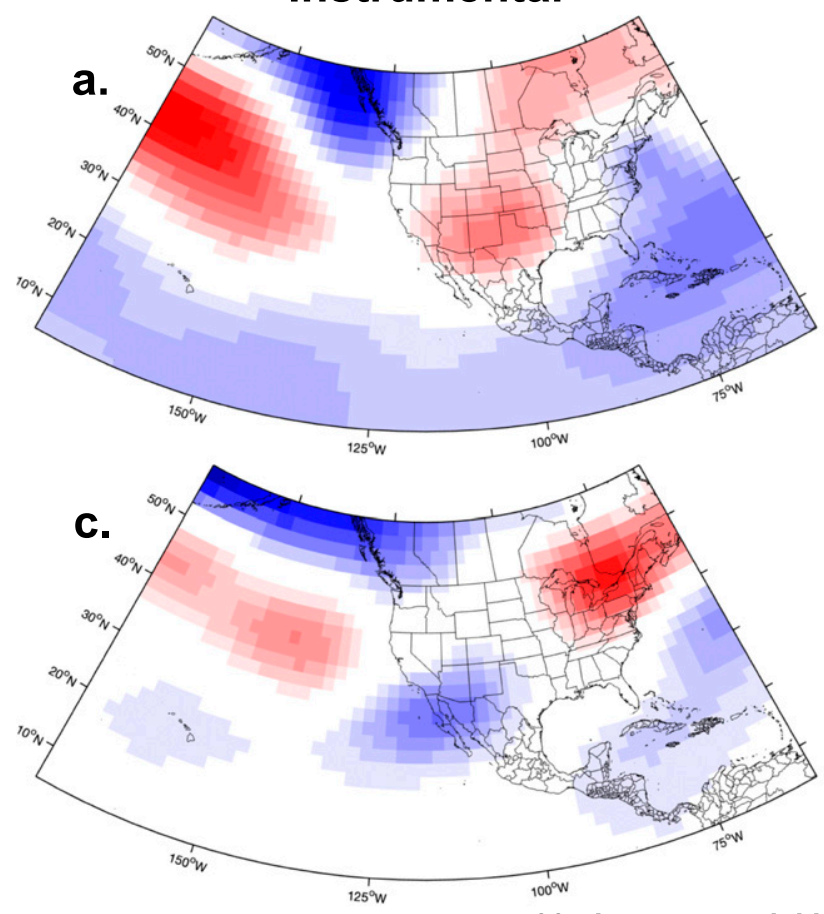
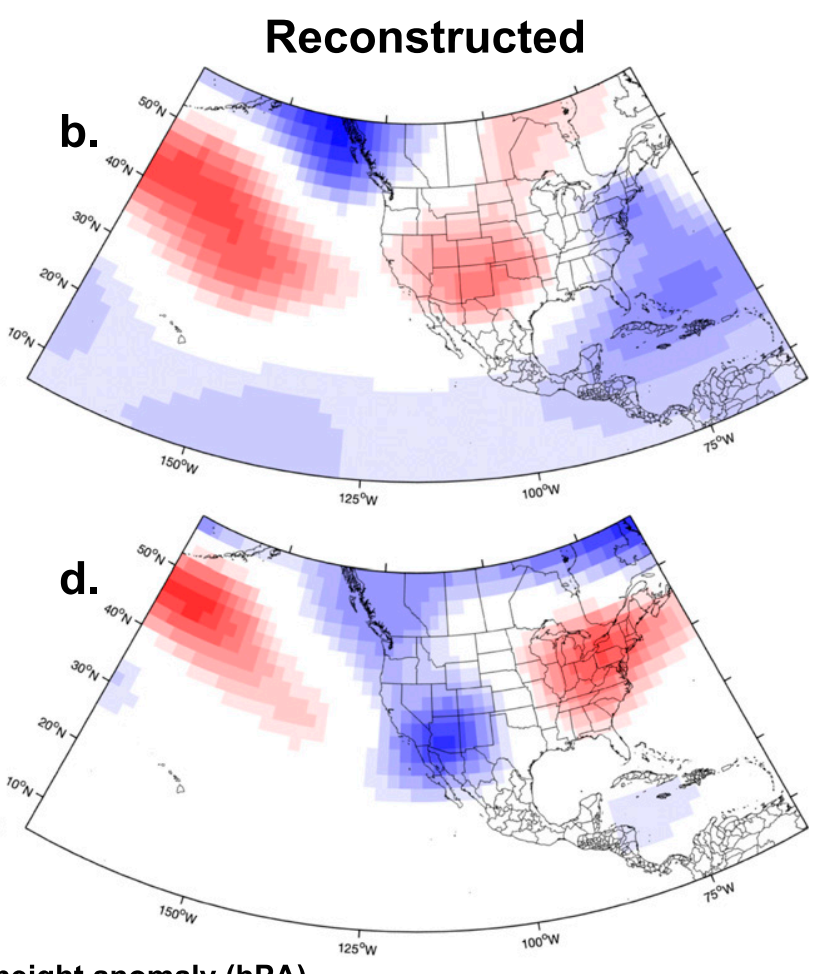

$500 \mathrm{mb}$ geopotential height anomaly (hPA)

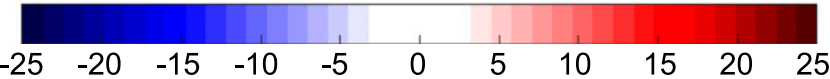

FIG. 8. Composite maps of 500-hPa geopotential height during the 10 largest drought relief events from 1895 to 1978 in the (a),(c) instrumental and (b),(d) reconstructed (top) cool-season (DJFMA) and (bottom) warm-season (MJJ) moisture estimates. The two lists share 6 of 10 years.

figures, both in the instrumental and reconstructed data. This high rate of relief is likely due to the contribution of summer rainfall to the annual total and is in line with the results produced by Karl et al. (1987). Summer precipitation in the region is partly driven by tropical cyclone (TC) activity, which can mitigate drought conditions (e.g., Maxwell et al. 2012; Misra and Bastola 2016). The TC season starts in June; however, most events occur in August or later (Kam et al. 2013) and although the MJJ reconstructions may contain some of this rainfall type, it is not possible to attribute the reconstructed drought relief/ reversals to any specific atmospheric setup. Reconstructed April drought over the MATL was more common prior to 1895, but reconstructed drought relief and reversals were less frequent. From 1500 to 1894, spring drought was ameliorated at $31.8 \%$ of grid points in the MATL region and terminated at $6.5 \%$ of grid points (Fig. 10a). Even when adjusting for the differences between instrumental and reconstructed percentages, the second half of the twentieth century is significantly less dry than the long-term estimates. Although the recent 5070 years appear unusual, periods prior to the instrumental era also experienced above average probabilities of drought relief and reversal (Fig. 10b; Pederson et al. 2013; Bishop et al. 2019), including the second half of the nineteenth century and the period from 1650 and 1750. These episodes of increased drought relief coincide with less extensive droughts (Fig. 10b).
Strong examples of relief and reversal for the MATL are reconstructed for 1574, 1778, and 1805 .

Drought relief as a result of MJJ rain has been rare in New Mexico (compared to MATL) in the observational period, and the reconstructions display similar low percentages for the centuries before instrumental data. There is some temporal variability in the relationship, including the decades around 1800 when late spring-early summer precipitation appears to have alleviated drought conditions at a greater extent than during any other period of analysis (Fig. 10c). The latesixteenth-century megadrought (Woodhouse and Overpeck 1998; Stahle et al. 2000) was the most severe spring drought to occur in New Mexico during the past 500 years (Fig. 10c) and includes 1585 for which every grid point in the regional box is

TABLE 1. Percentage of grid points in drought for instrumental and reconstructed data during the observational (1895-1978) and preobservational (1500-1894) periods for the two regions studied.

\begin{tabular}{|c|c|c|c|c|c|c|}
\hline & \multicolumn{2}{|c|}{$\begin{array}{c}\text { 1895-1978 } \\
\text { instrumental }\end{array}$} & \multicolumn{2}{|c|}{$\begin{array}{l}1895-1978 \\
\text { reconstructed }\end{array}$} & \multicolumn{2}{|c|}{$\begin{array}{l}1500-1894 \\
\text { reconstructed }\end{array}$} \\
\hline & Relief & Reversal & Relief & Reversal & Relief & Reversal \\
\hline MATL & 49.5 & 12.6 & 37.2 & 11.0 & 31.8 & 6.5 \\
\hline SW & 26.5 & 4.5 & 27.0 & 7.5 & 27.5 & 4.8 \\
\hline
\end{tabular}



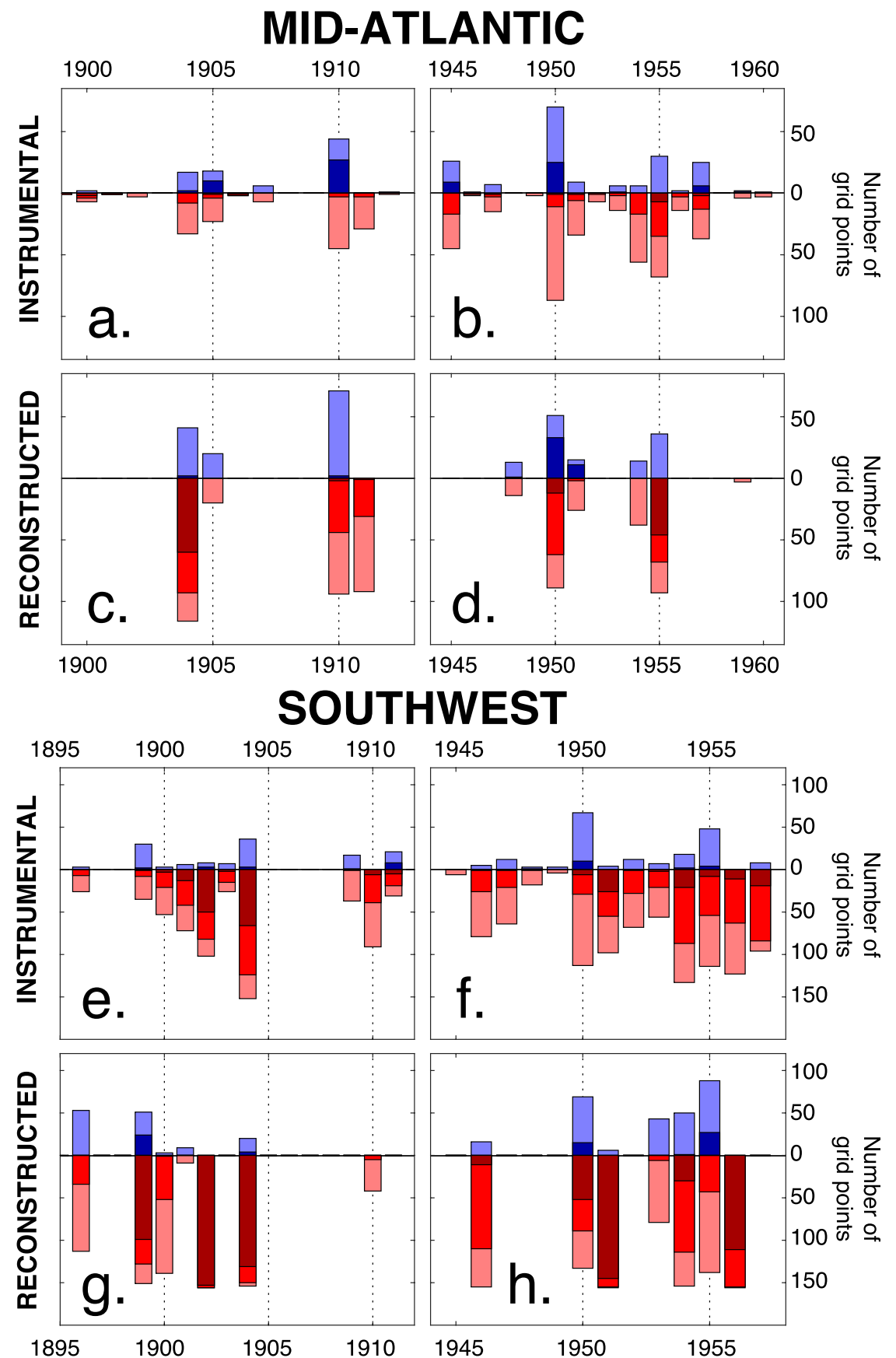

FIG. 9. The number of grid points within the regional boxes that recorded drought in April (i.e., April PDSI at or below $-2.0,-3.0$, and -4.0 ; red histograms) and the number of these points that were then ameliorated or terminated (blue and dark blue, respectively) for two extensive drought periods during the twentieth century (one during and one prior to the calibration period).

estimated to have experienced extreme April drought (PDSI $\leq-4)$. The reconstructions indicate that the megadrought could have continued for an additional decade if it were not for significant drought relief and reversal during the warm-season months. The region experienced its greatest period of extensive amelioration (Fig. 10d), likely driven by wet MJJ conditions, during 1780-1805 (Fig. 10c). Following this extended stretch of drought relief, the reconstructions indicate a period without any significant April drought, only rivaled in length by the early seventeenth century. 

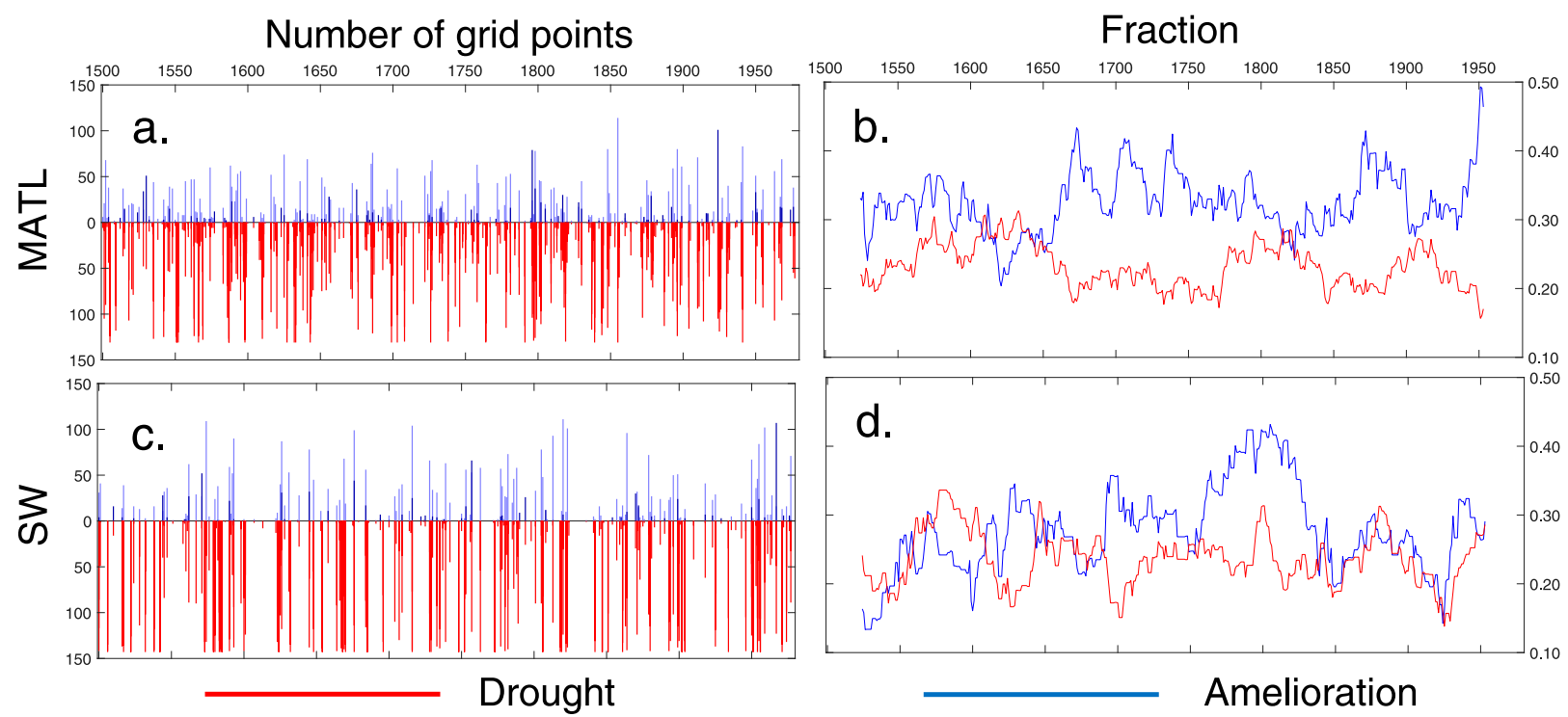

FIG. 10. The number of grid points that experienced at least moderate April drought (red color), and amelioration and termination in the subsequent summer months for 1500-1978 based on the rescaled reconstructions (blue colors) for the (a) mid-Atlantic and (c) Southwest regional boxes. Also shown are (b),(d) the 49-yr running mean of the fraction of grid points in the respective regions that displays at least moderate April drought (PDSI $\leq-2)$ and the fraction of those grid points experiencing amelioration in the subsequent summer months.

\section{d. Paleoclimate analogs of interseasonal drought dynamics}

Karl et al. (1987) analyzed 54 years of data (1931-84) in their study of drought relief and reversal probabilities for the United States. The results of the longer instrumental records used here are similar, with low chances of sufficient summer rainfalls over eastern United States and the West Coast to alleviate spring drought conditions (Fig. 1). The reconstructions suggest that the twentieth and early twenty-first centuries generally represent the long-term relationship between seasonal drought well. The reconstructions also display individual years and extended periods that fall outside the range of our current observational data. The NASPA contains new information on interseasonal drought variability, perhaps best exemplified by the consecutive years of drastic reversals experienced across Virginia and the Carolinas around 1800 (Fig. 11). The summer soil moisture estimates of the North American Drought Atlas (NADA; Cook et al. 1999) indicate near mean conditions for the region, while the NASPA displays clear opposite anomalies at a seasonal resolution. If it had not been for extensive MJJ rainfall, the period 1796-1802 could have rivaled the Lost Colony and Jamestown droughts two centuries prior (Stahle et al. 1998).

The long-term relationship between spring drought extent and magnitude of drought relief, as illustrated in Fig. 6b by running means, appears largely independent at the continental scale. Extreme years of large-scale reversals during the twentieth century, in the instrumental and reconstructed data alike, are related to positive $500-\mathrm{hPa}$ anomalies over the North Pacific Ocean in winter and spring, and low pressure systems developing over the continent in subsequent months (Fig. 8).
Conversely, the low-frequency relationship between spring drought extent and magnitude of drought relief at the regional scale in MATL and SW is strongly negative (Figs. 10b,d), likely due to land surface feedbacks. These results are in line with model experiments that highlight differing processes affecting drought development and relief at different spatial scales, and the possible exacerbation of climate dynamics by land-atmosphere interactions (Brubaker et al. 1993; Zhou et al. 2019).

The United States may have experienced the lowest percentage of drought area relieved over the past 500 years during the twentieth century (Fig. 6b). There have been large shifts in the relationship between cool- and warm-season drought at a regional scale, with some periods experiencing higher frequencies of relief and reversal events. These shifts appear to have lasted several decades and, in the case of MATL, represent century-long variations. The negative relationship between drought and amelioration extent recorded by the reconstructions in MATL is not apparent for the full period of analysis in New Mexico (Fig. 10d). However, the first $\sim 300$ years of analysis (1500-1800) do display a similar pattern (i.e., greater spatial extent of drought is followed by relatively less amelioration). Prior to 1800 , the fraction of grid points in drought with subsequent relief was negatively related to the spatial extent of drought but in the past 200 years there appears to be a positive relationship. Similar changes have been noted previously (Coats et al. 2015) and could play an important role in understanding current and future conditions (Cook et al. 2015), as it has been postulated that the North American monsoon may weaken (Hoell et al. 2016; Pascale et al. 2017) as global temperatures continue to rise. 


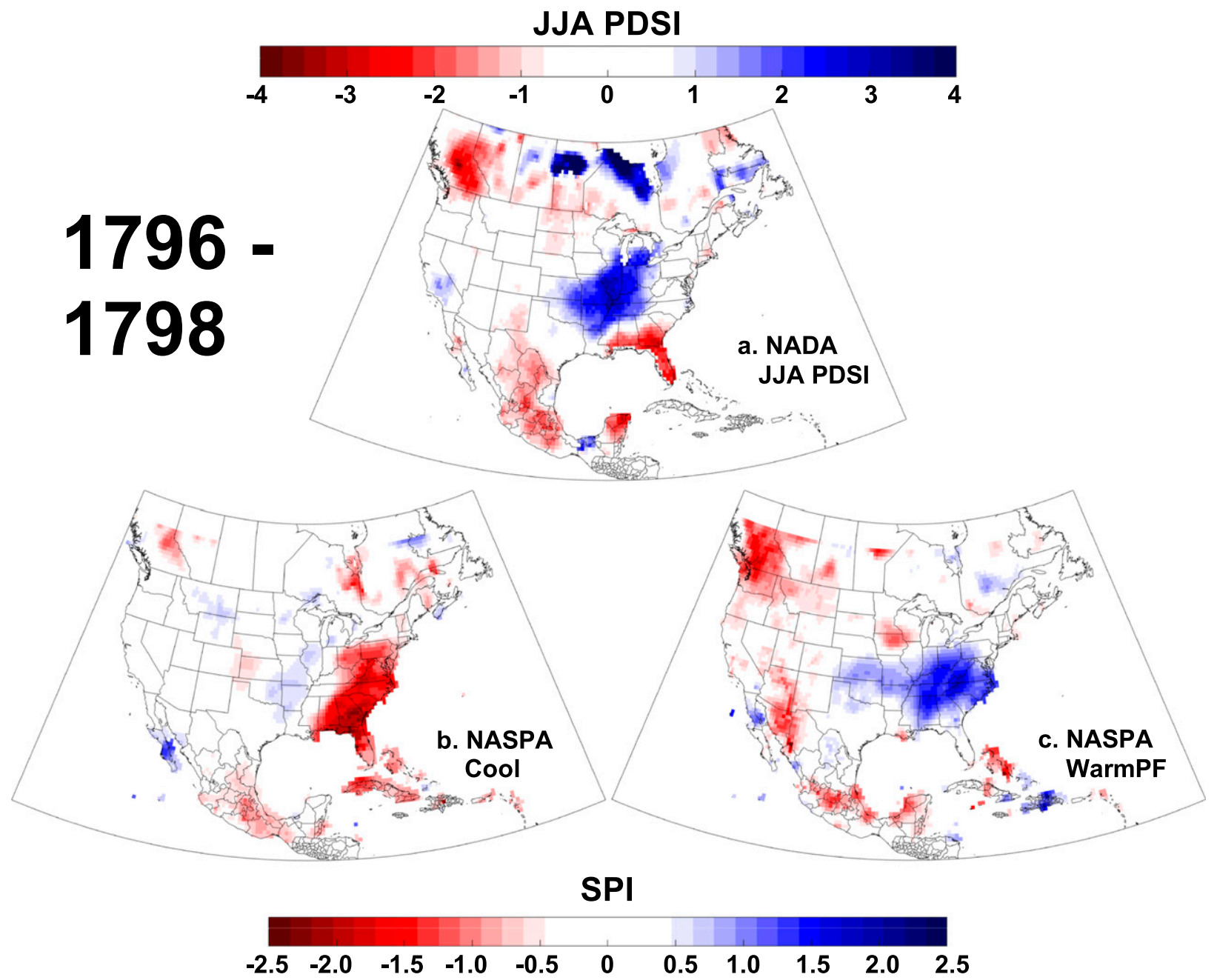

FIG. 11. Average reconstructed hydroclimate anomalies mapped for (a) JJA PDSI (NADA; Cook et al. 1999) and (b) DJFMA SPI and (c) MJJ SPI (NASPA; Stahle et al. 2020) for the period 1796-98.

\section{Conclusions}

Because the seasonal precipitation reconstructions generally agree with the instrumental data with respect to the frequency and magnitude of intra-annual drought relief and reversal, the NASPA provides a new perspective on the seasonal evolution of drought across North America.

These rescaled seasonal reconstructions provide many additional examples of cool-season drought relieved or fully reversed over the past 500 years. In some cases, the opposite spring to summer moisture conditions would be represented as near normal conditions in estimates of the growing-season soil moisture balance. From 1796 to 1798 , for example, the PDSI reconstructions in the NADA indicate near normal conditions over the Southeast, while the NASPA estimates the strong reversal from cool-season drought to warm-season wetness during these three consecutive years. The seasonal "flavor" of other well-known preinstrumental droughts are also estimated in the NASPA, including the megadrought of the late sixteenth century (Stahle et al. 2020).
The results presented in this paper also suggest that the NASPA captures the underlying dynamics that affect both large-scale and regional cool-to-warm-season drought variability. Drought relief and reversal are not only rare at a continental scale, but they also tend to result from large simultaneous changes in atmospheric circulation patterns over the North Pacific and North America, potentially in combination with land-atmosphere interactions. This involvement of the large-scale midlatitude circulation in drought relief and reversal offers some hope for the anticipation and forecasting of the meteorological conditions required to alleviate spring drought in the subsequent summer. The inferences concerning relief and reversal of spring drought are not obvious in the instrumental record where drought relief, and especially full termination, due to summer precipitation is very rare. Drought relief appears to have multiple causes, possibly both dynamic (e.g., the potential long wave pattern of 1967) and stochastic. These infrequent, high-consequence changes can now be examined in the paleoclimate data, especially at regional scales 
where high skill in cool- and warm-season hydroclimate reconstructions are possible.

Acknowledgments. We appreciate discussions with Dr. Edward Cook, as well as the work of all those who have contributed data to the ITRDB. We thank three anonymous reviewers for constructive comments, which have helped to clarify the paper. The National Science Foundation (Grant AGS-1266014) and InterAmerican Institute for Global Change Research (CRN 2047) funded this study.

Data availability statement. The NASPA reconstructions, and underlying tree-ring data, are available at ITRDB/NOAA Paleo (https://www.ncdc.noaa.gov/data-access/paleoclimatology-data/ datasets/tree-ring).

\section{REFERENCES}

Adams, D. K., and A. C. Comrie, 1997: The North American monsoon. Bull. Amer. Meteor. Soc., 78, 2197-2213, https://doi.org/ 10.1175/1520-0477(1997)078<2197:TNAM >2.0.CO;2.

Andreadis, K. M., E. A. Clark, A. W. Wood, A. F. Hamlet, and D. P. Lettenmaier, 2005: Twentieth-century drought in the conterminous United States. J. Hydrometeor., 6, 985-1001, https://doi.org/10.1175/JHM450.1.

Ault, T. R., 2020: On the essentials of drought in a changing climate. Science, 368, 256-260, https://doi.org/10.1126/science.aaz5492.

Becker, A., P. Finger, A. Meyer-Christoffer, B. Rudolf, K. Schamm, U. Schneider, and M. Ziese, 2013: A description of the global land-surface precipitation data products of the Global Precipitation Climatology Centre with sample applications including centennial (trend) analysis from 1901-present. Earth Syst. Sci. Data, 5, 71-99, https://doi.org/10.5194/essd-5-71-2013.

Betts, A. K., J. H. Ball, A. C. M. Beljaars, M. J. Miller, and P. A. Viterbo, 1996: The land surface-atmosphere interaction: A review based on observational and global modeling perspectives. J. Geophys. Res., 101, 7209-7225, https://doi.org/10.1029/95JD02135.

— , A. B. Tawfik, and R. L. Desjardins, 2017: Revisiting hydrometeorology using cloud and climate observations. J. Hydrometeor., 18, 939-955, https://doi.org/10.1175/JHM-D-16-0203.1.

Bishop, D. A., and Coauthors, 2019: Investigating the causes of increased twentieth-century precipitation over the southeastern United States. J. Climate, 32, 575-590, https://doi.org/ 10.1175/JCLI-D-18-0244.1.

Brubaker, K. L., D. Entekhabi, and P. S. Eagleson, 1993: Estimation of continental precipitation recycling. J. Climate, 6, 1077-1089, https:// doi.org/10.1175/1520-0442(1993)006<1077:EOCPR>2.0.CO;2.

Coats, S., B. I. Cook, J. E. Smerdon, and R. Seager, 2015: Winter-to-summer precipitation phasing in southwestern North America: A multi-century perspective from paleoclimatic model-data comparisons. J. Geophys. Res., 120, 8052-8064, https://doi.org/10.1002/2015JD023085.

Cook, B. I., T. R. Ault, and J. E. Smerdon, 2015: Unprecedented 21st century drought risk in the American Southwest and the central plains. Sci. Adv., 1, e1400082, https://doi.org/10.1126/sciadv.1400082.

Cook, E. R., D. M. Meko, D. W. Stahle, and M. K. Cleaveland, 1999: Drought reconstructions of the continental United States. J. Climate, 12, 1145-1162, https://doi.org/10.1175/1520-0442(1999) 012<1145:DRFTCU $>2.0 . C O ; 2$.

—, R. Seager, R. R. Heim Jr., R. S. Vose, C. Herweijer, and C. Woodhouse, 2010: Megadroughts in North America: Placing IPCC projections of hydroclimatic change in a long-term paleoclimate context. J. Quat. Sci., 25, 48-61, https://doi.org/10.1002/jqs.1303.
Dong, X., and Coauthors, 2011: Investigation of the 2006 drought and 2007 flood extremes at the Southern Great Plains through an integrative analysis of observations. J. Geophys. Res., 116, D03204, https://doi.org/10.1029/2010JD014776.

Griffin, D., and Coauthors, 2013: North American monsoon precipitation reconstructed from tree-ring latewood. Geophys. Res. Lett., 40, 954-958, https://doi.org/10.1002/grl.50184.

Hao, Z., A. AghaKouchak, N. Nakhjiri, and A. Farahmand, 2014: Global integrated drought monitoring and prediction system. Sci. Data, 1, 14001, https://doi.org/10.1038/sdata.2014.1.

Heim, R. R., 2002: A review of twentieth-century drought indices used in the United States. Bull. Amer. Meteor. Soc., 83, 11491166, https://doi.org/10.1175/1520-0477-83.8.1149.

Hoell, A., C. Funk, M. Barlow, and S. Shukla, 2016: Recent and possible future variations in the North American monsoon. The Monsoons and Climate Change, L. de Carvalho and C. Jones, Eds., Springer, 149-162, https://doi.org/10.1007/978-3-319-21650-8_7.

Huang, J., H. M. van den Dool, and K. P. Georgarakos, 1996: Analysis of model-calculated soil moisture over the United States (1931-1993) and applications to long-range temperature forecasts. J. Climate, 9, 1350-1362, https://doi.org/10.1175/ 1520-0442(1996)009<1350:AOMCSM>2.0.CO;2.

Kam, J., J. Sheffield, X. Yuan, and E. F. Wood, 2013: The influence of Atlantic tropical cyclones on drought over the eastern United States (1980-2007). J. Climate, 26, 3067-3086, https:// doi.org/10.1175/JCLI-D-12-00244.1.

Karl, T., F. Quinlan, and D. S. Ezell, 1987: Drought termination and amelioration: Its climatological probability. J. Appl. Meteor. Climatol., 26, 1198-1209, https://doi.org/10.1175/15200450(1987)026<1198:DTAAIC > 2.0.CO;2.

Koster, R. D., M. J. Suarez, and M. Heiser, 2000: Variance and predictability of precipitation at seasonal-to-interannual timescales. J. Hydrometeor., 1, 26-46, https://doi.org/10.1175/15257541(2000)001<0026:VAPOPA > 2.0.CO;2.

Maurer, E. P., A. W. Wood, J. C. Adam, D. P. Lettenmaier, and B. Nijssen, 2002: A long-term hydrologically based dataset of land surface fluxes and states for the conterminous United States. J. Climate, 15, 3237-3251, https://doi.org/10.1175/15200442(2002)015<3237:ALTHBD>2.0.CO;2.

Maxwell, J. T., P. T. Soulé, J. T. Ortegren, and P. A. Knapp, 2012: Drought-busting tropical cyclones in the southeastern Atlantic United States: 1950-2008. Ann. Assoc. Amer. Geogr., 102, 259275, https://doi.org/10.1080/00045608.2011.596377.

Misra, V., and S. Bastola, 2016: Reconciling droughts and landfalling tropical cyclones in the southeastern United States. Climate Dyn., 46, 1277-1286, https://doi.org/10.1007/s00382015-2645-7.

Mock, C. J., 2008: Tropical cyclone variations in Louisiana, U.S.A., since the late eighteenth century. Geochem. Geophys. Geosyst., 9, Q05V02, https://doi.org/10.1029/2007GC001846.

Otkin, J. A., M. C. Anderson, C. Hain, and M. Svoboda, 2015: Using temporal changes in drought indices to generate probabilistic drought intensification forecasts. J. Hydrometeor., 16, 88-105, https://doi.org/10.1175/JHM-D-14-0064.1.

Palmer, W. C., 1965: Meteorological drought. Weather Bureau Research Paper 45, 85 pp., http://www.ncdc.noaa.gov/tempand-precip/drought/docs/palmer.pdf.

Pascale, S., W. R. Boos, S. Bordoni, T. L. Delworth, S. B. Kapnick, H. Murakami, G. A. Vecchi, and W. Zhang, 2017: Weakening of the North American monsoon with global warming. Nat. Climate Change, 7, 806-812, https://doi.org/10.1038/nclimate3412.

Pederson, N., A. R. Bell, E. R. Cook, U. Lall, N. Devineni, R. Seager, K. Eggleston, and K. P. Vranes, 2013: Is an epic pluvial masking the 
water insecurity of the Greater New York City region? J. Climate, 26, 1339-1354, https://doi.org/10.1175/JCLI-D-11-00723.1.

Polade, S. D., A. Gershunov, D. R. Cayan, M. D. Dettinger, and D. W. Pierce, 2017: Precipitation in a warming world: Assessing projected hydro-climate changes in California and other Mediterranean climate regions. Sci. Rep., 7, 10783, https://doi.org/10.1038/s41598-017-11285-y.

Schneider, U., A. Becker, P. Finger, A. Meyer-Christoffer, and M. Ziese, 2018: GPCC Full Data Monthly Product Version 2018 at $0.5^{\circ}$ : Monthly land-surface precipitation from rain-gauges built on GTS-based and historical data. DWD, accessed 1 February 2020, https://doi.org/10.5676/DWD_GPCC/FD_M_V2018_050.

Schumacher, R. S., and R. H. Johnson, 2006: Characteristics of U.S. extreme rain events during 1999-2003. Wea. Forecasting, 21, 69-85, https://doi.org/10.1175/WAF900.1.

Slivinski, L. C., and Coauthors, 2019: Towards a more reliable historical reanalysis: Improvements for version 3 of the Twentieth Century Reanalysis system. Quart. J. Roy. Meteor. Soc., 145, 2876-2908, https://doi.org/10.1002/qj.3598.

Stahle, D. W., M. K. Cleaveland, D. B. Blanton, M. D. Therrell, and D. A. Gay, 1998: The Lost Colony and Jamestown droughts. Science, 280, 564-567, https://doi.org/10.1126/science.280.5363.564.

— E. R. Cook, M. K. Cleaveland, M. D. Therrell, D. M. Meko, H. D. Grissino-Mayer, E. Watson, and B. H. Luckman, 2000: Tree-ring data document 16th century megadrought over North America. Eos, Trans. Amer. Geophys. Union, 81, 121125, https://doi.org/10.1029/00EO00076.

—_ and Coauthors, 2016: The Mexican Drought Atlas: Tree-ring reconstructions of soil moisture balance during the late preHispanic, colonial, and modern eras. Quat. Sci. Rev., 149, 34 60, https://doi.org/10.1016/j.quascirev.2016.06.018.
— , and Coauthors, 2020: Dynamics, variability, and change in seasonal precipitation reconstructions for North America. J. Climate, 33, 3173-3195, https://doi.org/10.1175/JCLI-D-190270.1.

Torbenson, M. C. A., and D. W. Stahle, 2018: The relationship between cool and warm season moisture over the central United States, 1685-2015. J. Climate, 31, 7909-7924, https:// doi.org/10.1175/JCLI-D-17-0593.1.

van der Schrier, G., J. Barichivich, K. R. Briffa, and P. D. Jones, 2013: A scPDSI-based global data set of dry and wet spells for 1901-2009. J. Geophys. Res., 118, 4025-4048, https://doi.org/ 10.1002/jgrd.50355.

Wilhite, D. A., 2000: Drought as a natural hazard: Concepts and definitions. Drought: A Global Assessment, D. A. Wilhite, Ed., Routledge, 3-18.

Woodhouse, C. A., and J. T. Overpeck, 1998: 2000 years of drought variability in the central United States. Bull. Amer. Meteor. Soc., 79, 2693-2714, https://doi.org/10.1175/1520-0477(1998) 079<2693:YODVIT>2.0.CO;2.

Zhou, S., and Coauthors, 2019: Land-atmosphere feedbacks exacerbate concurrent soil drought and atmospheric aridity. Proc. Natl. Acad. Sci. USA, 116, 18 848-18 853, https://doi.org/ 10.1073/pnas.1904955116.

Zhu, C., D. P. Lettenmaier, and T. Cavazos, 2005: The role of antecedent land surface conditions on North American monsoon rainfall variability. J. Climate, 18, 3104-3121, https://doi.org/ 10.1175/JCLI3387.1.

— T. Cavazos, and D. P. Lettenmaier, 2007: The role of antecedent land surface conditions on warm season precipitation over northwestern Mexico. J. Climate, 20, 1774-1791, https:// doi.org/10.1175/JCLI4085.1. 